\title{
Poor control of the horse chestnut leafminer, Cameraria ohridella (Lepidoptera: Gracillariidae), by native European parasitoids: a synchronisation problem
}

\author{
GISELHER GRABENWEGER
}

Institute of Plant Protection, University of Natural Resources and Applied Life Sciences, Peter-Jordan-Straße 82, A-1190 Vienna, Austria; e-mail: giselher.grabenweger@boku.ac.at

Key words. Cameraria ohridella, Gracillariidae, introduced host, native parasitoids, Chalcidoidea, synchronisation

\begin{abstract}
Horse chestnut trees in many regions of Europe have suffered from epidemic infestations of $C$. ohridella for more than ten years. There has been no obvious decrease in the infestation level anywhere on the continent. One reason is, that the native natural enemies have not been able to control mass outbreaks of the leafminer. Parasitoid Hymenoptera have very little impact on the first generation of the moth in early summer, regardless of the number of parasitoids that overwintered in horse chestnut leaves. This study revealed that there is a considerable time lag between the emergence of the parasitoids from the leaflitter in spring and the appearance of suitable host instars in early summer. The poor control of $C$. ohridella by natural enemies may partly be due to the poor synchronisation between the life cycles of the introduced host and native parasitoid wasps.
\end{abstract}

\section{INTRODUCTION}

Cameraria ohridella Deschka \& Dimic 1986 is undoubtedly one of the best known insect pests in many European countries. This is mainly because the host plant of this leafminer, the common horse chestnut Aesculus hippocastanum L., is a popular ornamental tree and present in public parks, avenues and private yards of almost every large city. For many years the trees have been continuously heavily infested by the larvae of the horse chestnut leafminer, which cause severe damage. The symptoms are easily detectable even by non-scientists. In comparison with mass outbreaks of other leafmining moths, the invasion of $C$. ohridella in Europe is remarkable for two reasons. First, the abundance of the mining larvae in the leaves exceeds by far that of other closely related species. Deschka (1993) stated that during thirty years of practice he had never previously observed such high numbers of miners per leaf. Second, the infestation levels of the horse chestnut trees have not declined anywhere in Europe due to natural control. At several locations the horse chestnut leafminer has remained at epidemic population densities for more than ten years, e.g. in Enns (Austria) or Zagreb (Croatia), where the leafmines were first detected in 1989 (Puchberger, 1995; Maceljski \& Bertić, 1996).

It is not known whether the long term effect of continuous defoliation is fatal for horse chestnut trees. Nevertheless, this tree needs to be protected in some way because of its importance in recreational areas in and around cities. Therefore, research has focused on the control of $C$. ohridella, e.g. Blümel \& Hausdorf (1996), Krehan (1997), Šefrová (2001). Aside from the implementation of a plant protection scheme the investigations raised another scientifically interesting question. Why are the native European parasitoids unable to control the horse chestnut leafminer?

Zwölfer and Pschorn-Walcher (1968) studied the effect of native parasitoids on several pest insects introduced into North America. They listed some important factors influencing the probability that the native parasitoids will control the introduced host species.

1. Adaptation to a foreign host insect is more likely if other close relatives of the pest species already exist in the environment. This precondition is fulfilled in the case of C. ohridella, since leafmining moths are quite common even in urban areas, e.g. Phyllonorycter platani and Phyllonorycter robiniella in Southern and Central Europe.

2. There are many examples of closely related parasitoid species attacking closely related host insects. Parasitoids from genera already involved in the parasitism of the host in its original area will more likely integrate the exotic species into their spectrum. Of course this host shift may not necessarily result in effective pest control. Unfortunately, the origin and therefore the natural enemy complex of $C$. ohridella are unknown.

3. The existence of polyphagous parasitoids with broad ecological amplitudes enhance the chances of effectively controlling a new pest. Investigations on the ecology of particular parasitoids are rare, nevertheless, some information may be extracted from the literature on various phytophagous host insects. Hellrigl (2001) has compiled important data on the parasitoids of the horse chestnut leafminer. Some species reared from $C$. ohridella parasitize nearly every leafmining insect in Europe, which indicates an ability to survive in a great variety of environmental conditions.

4. Rarely does an introduced pest insect encounter a highly flexible native parasitoid species, which is able to adapt and become an important natural enemy of the new host. So far none of the horse chestnut leafminer's parasitoid complex have become important antagonists.

5. Specific physiological features or peculiarities in the pest's life cycle may prevent a high incidence of parasitism. The latter may cause poor synchronisation of the life cycles of native antagonists with that of the introduced host. The control of a new pest is only possible if the life cycles of the parasitoids and the host are synchronised. Therefore, the lack of suitable hosts when parasitoids are ovipositing will inhibit the adaptation process.

Results from previous studies on C. ohridella revealed evidence for poor synchronisation especially in spring. The incidence of parasitism of the leafminer's first generation in spring is uniformly low, regardless of the incidence of parasitism of the preceding generation in autumn (Grabenweger, unpubl.). The parasitoid complex attacking $C$. ohridella in autumn is not similar to that found in spring (Grabenweger, 1998). This suggests that the parasitoids that diapause in mines of $C$. ohridella 
TABLE 1. Emergence of parasitoids (number of individuals) from horse chestnut leaflitter recorded at weekly intervals in spring 2001 (photoeclector data, $\mathrm{N}=311$ ).

\begin{tabular}{|c|c|c|c|c|c|c|c|c|c|c|c|c|c|c|c|c|c|c|}
\hline \multirow[b]{2}{*}{$\begin{array}{l}\text { parasitoid } \\
\text { species (family) }\end{array}$} & \multicolumn{17}{|c|}{ Collection date } & \multirow[b]{2}{*}{ total } \\
\hline & $\stackrel{\dot{r}}{r}$ & $\ddot{\dot{y}}$ & $\dot{\vec{n}}$ & $\dot{j}$ & $\begin{array}{l}\dot{r} \\
\dot{\nabla}\end{array}$ & $\stackrel{+}{\Xi}$ & $\underset{\dot{\infty}}{\dot{\infty}}$ & 㐫 & $\dot{i}$ & $\dot{n}$ & $\ddot{n}$ & $\ddot{n}$ & $\ddot{n}$ & $\begin{array}{l}\dot{0} \\
\dot{0}\end{array}$ & $\stackrel{\dot{\varphi}}{\ddot{n}}$ & $\stackrel{\dot{0}}{\dot{\imath}}$ & $\stackrel{\dot{\varphi}}{\stackrel{\sim}{N}}$ & \\
\hline Pnigalio agraules (Eulophidae) & & & & & 5 & 17 & 19 & 7 & 10 & 3 & & 1 & & & & & & 62 \\
\hline $\begin{array}{l}\text { Pnigalio pectinicornis } \\
\text { (Eulophidae) }\end{array}$ & & & & & & & & 2 & & & & & & & & & & 2 \\
\hline $\begin{array}{l}\text { Minotetrastichus frontalis } \\
\text { (Eulophidae) }\end{array}$ & & & & & & 26 & 41 & 64 & 61 & 9 & 3 & 3 & & & & & & 207 \\
\hline Cirrospilus vittatus (Eulophidae) & & & & & & & & 1 & 4 & & & & & & & & & 5 \\
\hline $\begin{array}{l}\text { Closterocerus trifasciatus } \\
\text { (Eulophidae) }\end{array}$ & & & & & & & & 3 & 8 & 3 & 5 & 1 & & & & & & 20 \\
\hline $\begin{array}{l}\text { Chrysocharis nephereus } \\
\text { (Eulophidae) }\end{array}$ & & & & & & & & 3 & & & & & & & & & & 3 \\
\hline Eupelmus urozonus (Eupelmidae) & & & & & & & & & & & & & 1 & & & & & 1 \\
\hline $\begin{array}{l}\text { Pteromalus cf. semotus } \\
\text { (Pteromalidae) }\end{array}$ & & & & 1 & & & & 3 & 4 & 1 & & & & & & & & 9 \\
\hline Colastes braconius (Braconidae) & & & & & & & & 1 & & & & & & & & & & 1 \\
\hline $\begin{array}{l}\text { Itoplectis alternans } \\
\text { (Ichneumonidae) }\end{array}$ & & & & & & & & 1 & & & & & & & & & & 1 \\
\hline
\end{tabular}

in autumn are not the ones that attack the first leafminer generation in spring. In this study the time of emergence of the parasitoids after diapause and the phenology of the leafminer in spring are compared. The aim was to find out whether the low levels of parasitism of the horse chestnut leafminer by native European parasitoids are due to poor synchronisation.

\section{MATERIALS AND METHODS}

Data from three experiments are analysed in the present paper.

\section{Emergence of parasitoids after diapause}

The appearance of the parasitoids in spring 2001 was recorded in four different public parks south of Vienna, Austria. Leaves are regularly removed in autumn, yet some leaflitter remains beneath shrubs and bushes at these sites. Without exception, the parasitoids diapause in the mines of their hosts and overwinter in the shed horse chestnut leaves. 20 litres of horse chestnut leaflitter, which has been heavily infested by the leafminer were put into a photoeclector in late autumn. The photoeclectors were set up in shady places at the sampling locations and left there during the winter and following spring until several weeks after the last parasitoids emerged from the leaves (end of June). The photoeclectors were checked weekly and the traps on top of the eclectors were replaced by new ones if they contained insects.

\section{Phenology of $C$. ohridella}

The second experiment dealt with the development of the host's spring generation. As soon as the moths from the overwintering generation began to emerge from the leaflitter (the first moth was observed on $11^{\text {th }}$ of April in 2001), the upper surfaces of the new leaves on the surrounding horse chestnut trees were examined weekly for $C$. ohridella eggs and mines. After the appearance of the first mines at the beginning of May, 10 leaves were picked at random from the lower branches of the trees every week at one location. 10 mines per leaf were dissected and the developmental stage of each leafminer instar was recorded. All dead, injured or parasitized stages were excluded from analysis because it was not possible to determine when their development stopped. Dissections were continued until the beginning of July, when the majority of the first leafminer generation had completed their development and the adults had emerged from the mines.

\section{Parasitism of the first generation}

Preimaginal instars of parasitoids, which were detected during dissection of the mines were isolated and reared and the adults identified. The number of parasitoids was correlated with the sampling dates, the juvenile host stages and the developmental status of the leafminers in the leaves. For the latter the stages were ranked $\left(1^{\text {st }}, 2^{\text {nd }}, 3^{\text {rd }}\right.$ and $4^{\text {th }}$ feeding instar $(1-4), 1^{\text {st }}$ and $2^{\text {nd }}$ spinning instar $(5,6)$ and pupa $(7)$, emerged moths were not included) and the ranks were multiplied by the abundances of the corresponding stages on each sampling date. The developmental status allows the integration of the larval development into the time scale.

\section{RESULTS}

\section{Emergence of parasitoids after diapause}

The first parasitoid to emerge at the end of March was Pteromalus cf. semotus (Walker). The majority of the parasitoids emerged three to five weeks later (Table 1). Three eulophid species were particularly abundant. The most abundant, Minotetrastichus frontalis (Nees), emerged between mid April and mid May. The peak emergence of Pnigalio agraules (Walker) was about a week earlier than that of $M$. frontalis. Most of the Closterocerus trifasciatus Westwood emerged a week later. By the beginning of May, more than $90 \%$ of the parasitoids had emerged from the leaflitter. At this time, the first $C$. ohridella females started to lay their eggs on the young horse chestnut leaves.

\section{Phenology of $C$. ohridella in spring}

The first intensive survey of the horse chestnut leaves was carried out on May 6. At this time, only one first instar mine was found. One week later, there were more than five $C$. ohridella larvae per leaflet and the dissection of mines was started. After the end of May, more than $50 \%$ of the preimaginal stages in the leaves were late feeding larvae, spinning instars or pupae of the moth (Table 2). The sample taken on the $2^{\text {nd }}$ June was the first with all preimaginal leafminer stages present in the 
TABLE 2. Phenology of the $1^{\text {st }}$ generation (and part of the $2^{\text {nd }}$ generation) of $C$. ohridella (number of alive stages and empty pupal exuviae found in horse chestnut leaves in the spring and early summer of 2001, $\mathrm{N}=798$ )

\begin{tabular}{|c|c|c|c|c|c|c|c|c|c|}
\hline \multirow{2}{*}{$\begin{array}{l}\text { Developmental stage } \\
\text { of } C \text {. ohridella }\end{array}$} & \multicolumn{9}{|c|}{ Dissection date } \\
\hline & 12.5. & 20.5 & 27.5 . & 2. 6. & 10.6 . & 16. 6. & 25.6. & 1.7. & 8. 7. \\
\hline $1^{\text {st }}$ larval instars & 40 & 21 & 13 & 6 & 1 & & & 1 & 23 \\
\hline $2^{\text {nd }}$ larval instars & 46 & 19 & 24 & 13 & 2 & 4 & & & 8 \\
\hline $3^{\text {rd }}$ larval instars & 6 & 53 & 24 & 25 & 23 & 10 & & & 8 \\
\hline $4^{\text {th }}$ larval instars & & & 22 & 20 & 31 & 40 & 11 & 2 & \\
\hline $1^{\text {st }}$ spinning instars & & & & 7 & 11 & 9 & 4 & & 1 \\
\hline $2^{\text {nd }}$ spinning instars & & & & 9 & 2 & 8 & 9 & 7 & \\
\hline pupae & & & & 8 & 18 & 19 & 47 & 49 & 15 \\
\hline adult moths & & & & & & & 13 & 27 & 39 \\
\hline
\end{tabular}

leaves. In addition, the last adults of the overwintering generation were still flying and laying eggs. At the end of June, empty pupal exuviae protruding from the leaf surface were detected, which indicated that the first leafminers had completed their development and emerged from the mines. Larvae of the second generation were observed at the beginning of July. Nevertheless, the number of juvenile stages in the leaves decreased significantly during this period due to adult emergence.

\section{Parasitism of the first generation}

Only 35 parasitized mines were recorded during dissections. Minotetrastichus frontalis was the most frequent parasitoid. Only a few individuals of Chrysocharis nephereus (Walker), Sympiesis sericeicornis (Nees) and Pediobius saulius (Walker) were found (Table 3 ). The latter two species did not occur in the photoeclector samples.

None of the first instar larvae was parasitized and the two parasitoids found in second instar larvae did not reach adulthood. A few parasitoids occurred in the third larval instar and several more in the fourth stage. In relation to their abundances in the leaves (cf. Table 2), the two spinning stages were the most frequently attacked and pupal parasitism was relatively high. The correlation between the number of parasitoids and the age of the juvenile instars is highly significant (Spearmans $\rho=$ 0.893; $\alpha=0.007)$.

The first parasitized larvae were detected at the end of May, the majority of the mines (more than $68 \%$ of all parasitized ones), however, were attacked after mid June. The number of parasitoids reared increased steadily with sampling date except for the last sample. Nevertheless, the correlation between the number of parasitoids and sampling date is significant (Spearmans $\rho=0.681 ; \alpha=0.044)$. If the developmental status of the leafminer's population is used instead of the dissection date, the correlation is highly significant (Spearmans $\rho=0.874 ; \alpha=$ $0.002)$.

\section{DISCUSSION}

It is clear from Table 3 and the highly significant correlation that parasitoids prefer late larval instars and pupae as hosts. Previous investigations on the host stage preferences of chalcidoid species, including M. frontalis, gave similar results (Freise, 2001, Grabenweger, 2003).

Higher numbers of third instar larvae, which is the first host stage suitable for parasitoid development, occur only after mid May. This finding was corroborated by the dissection results, since the first parasitized mines were found at the end of May. The samples with larger numbers of late instar larvae and pupae, the preferred host instars, were collected two or three weeks later.

Since the leafminer larvae grow older in the process of development, parasitism should increase in the course of the season. This was born out by the significant correlation between parasitism and sampling date. At first sight, the low level of parasitism in the last sample (see Table 3 ) contravenes this result. The explanation is that most of the leafminers of the first generation had completed their development at the end of June or the beginning of July. They emerged from the mines and were not present as hosts any more. At the same time, young second generation larvae were present in the leaves. In the last sample,

TABLE 3. Parasitoids ${ }^{1}$ found in the mines of the $1^{\text {st }}$ generation of $C$. ohridella $(\mathrm{N}=35)$

\begin{tabular}{|c|c|c|c|c|c|c|c|c|c|}
\hline \multirow{2}{*}{ Developmental stage of host } & \multicolumn{9}{|c|}{ Dissection date } \\
\hline & 12. 5. & 20.5 . & 27.5 . & 2. 6. & 10.6. & 16.6. & 25.6 . & 1.7. & 8. 7. \\
\hline \multicolumn{10}{|l|}{$1^{\text {st }}$ larval instars } \\
\hline $2^{\text {nd }}$ larval instars & & & & & & & $2 \mathrm{id}$ & & \\
\hline $3^{\text {rd }}$ larval instars & & & $\begin{array}{l}2 \mathrm{Mf} \\
1 \mathrm{id}\end{array}$ & & $1 \mathrm{Mf}$ & & $1 \mathrm{Mf}$ & & \\
\hline $4^{\text {th }}$ larval instars & & & $2 \mathrm{id}$ & $1 \mathrm{Mf}$ & & $3 \mathrm{Mf}$ & & $1 \mathrm{Mf}$ & \\
\hline $1^{\text {st }}$ spinning instars & & & & & & $\begin{array}{l}1 \mathrm{Mf} \\
1 \mathrm{Cn}\end{array}$ & $1 \mathrm{Mf}$ & $1 \mathrm{Mf}$ & \\
\hline $2^{\text {nd }}$ spinning instars & & & & & $1 \mathrm{Mf}$ & & $3 \mathrm{Mf}$ & $\begin{array}{l}1 \mathrm{Ss} \\
1 \mathrm{Mf}\end{array}$ & $\begin{array}{l}1 \mathrm{Mf} \\
1 \mathrm{Ps}\end{array}$ \\
\hline pupae & & & & & $3 \mathrm{Mf}$ & $1 \mathrm{Mf}$ & $2 \mathrm{Mf}$ & $\begin{array}{l}2 \mathrm{Ss} \\
1 \mathrm{Mf}\end{array}$ & \\
\hline
\end{tabular}

${ }^{1} \mathrm{Mf}=$ Minotetrastichus frontalis, $\mathrm{Cn}=$ Chrysocharis nephereus, $\mathrm{Ss}=$ Sympiesis sericeicornis, $\mathrm{Ps}=$ Pediobius saulius, $\mathrm{id}=$ parasitoid did not develop to adult stage, determination impossible. 
they accounted for more than two thirds of the stages under consideration (see Table 2). For this reason, the number of suitable host stages present in the leaves decreased in the last sample, although it was taken at the end of the moth's first generation.

In contrast to the sampling dates, the developmental status of the leafminer's population takes into account the overlap between the two leafminer generations. As with the analysis of the larval stages, the correlation between the developmental status of the host population and parasitism gave highly significant results. Apparently, the parasitoids mainly attacked $C$. ohridella in the final stages of development at the end of the investigation period.

A comparison of the photoeclector (Table 1) and the phenology data (Table 2) reveals a considerable time lag between the emergence of the parasitoids from the horse chestnut leaflitter and the appearance of suitable host stages. The end of the diapause of the parasitoids coincided with the emergence of the adult moths of the overwintering generation. Similar observations were made in South Tyrol, Italy (Hellrigl, 2003). Between mid April and beginning of May bud burst and growth of horse chestnut leaves occurred and $C$. ohridella adults swarmed. No mines, not even eggs were found at that time. Nevertheless, most of the parasitoids had emerged.

$S$. sericeicornis and $P$. saulius were reared from the leaves dissected in spring, although no adults emerged from the leaflitter collected at the same sites. This indicates that the parasitoid complex associated with the leafminer's first generation comes from sources other than horse chestnut leaflitter. On the other hand, $M$. frontalis dominated the parasitoid complex of both, the first and previous diapausing generation of the leafminer. However, this does not prove that the M. frontalis larvae found in the mines are the offspring of the individuals that hibernated in the horse chestnut leaflitter. M. frontalis is recorded from a large number of mostly leafmining hosts (more than 60 different host records are available, see Noyes, 2002). This species probably occurs in a wide range of habitats and is able to switch to $C$. ohridella from another host species throughout the season.

These results indicate that the majority of the parasitoids would have to survive at least a month in order to encounter leafminer instars suitable for parasitism. The lifespan of adult chalcidoids varies from a few days to several months (BendelJanssen, 1977). Therefore, it is theoretically possible for some parasitoids to survive until the first suitable hosts develop in horse chestnut leaves. On the other hand, the parasitoid wasps reared from the leaves are known to be polyphagous (Noyes, 2002; Hellrigl, 2001). Therefore, in the weeks before they find the preferred $C$. ohridella instars, the parasitoids will probably encounter lots of other potential host species infesting other host plants.

This implies that the parasitoids attacking the first generation of $C$. ohridella in early summer are not those that emerged from the horse chestnut leaflitter in spring. Consequently, the parasitization of this leafminer's first generation by native parasitoids starts from the same low level each year.

\section{CONCLUSION}

The annual break in the adaptation process of the native parasitoids to the new host may account for the persistently low parasitism levels of $C$. ohridella, especially in the first generation. Therefore, the low incidence of parasitism of the horse chestnut leafminer by European chalcidoids is at least in part a matter of poor synchronisation between the host insect and its natural enemies. Cornell \& Hawkins (1993) investigated the accumulation of native parasitoids on introduced herbivores. Some of their examples indicate that even specialist parasitoid
Hymenoptera may overcome phenological incompatibilities and switch to a new host. However, the time required for this will probably span evolutionary rather than ecological time scales. It is unlikely that the parasitoid species considered in this study will control C. ohridella in the near future.

ACKNOWLEDGEMENTS. Many thanks go to Christa Lethmayer, Austrian Agency for Health and Food Safety, Vienna, for helpful comments on the manuscript. I am also grateful to Peter Schausberger, University of Natural Resources and Applied Life Sciences, Vienna, for constructive criticism on the manuscript and correction of English. The studies which contributed to this paper were financially supported by the Government of Lower Austria by means of the "Landschaftsfonds" and by the European Commission as part of the FP5 project CONTROCAM, QLK5-CT-2000-01684.

\section{REFERENCES}

Bendel-Janssen M. 1977: Zur Biologie, Ökologie und Ethologie der Chalcidoidea (Hym.). Mitt. Biol. Bundesanst. LandForstwirtsch. Berl.-Dahlem 176: 163.

BLÜMEL S. \& HAuSdoRF H. 1996: Versuche zur Bekämpfung der Roßkastanienminiermotte. Gärtner \& Florist 10: 4-6.

Cornell H.V. \& Hawkins B.A. 1993: Accumulation of native parasitoid species on introduced herbivores: A comparison of hosts as natives and hosts as invaders. Am. Nat. 141: 847-865.

DeschKa G. 1993: Die Miniermotte Cameraria ohridella Deschka \& Dimic, eine Gefahr für die Roßkastanie Aesculus hippocastanum L. (Insecta: Lepidoptera: Lithocolletidae). Linzer Biol. Beitr. 25: $141-148$.

FREISE J. 2001: Untersuchungen zur Biologie und Ökologie der Roßkastanien-Miniermotte, Cameraria ohridella Desch. \& Dim. (Lep., Gracillariidae). PhD Thesis, Dept. Appl. Zool., Technical University of Munich, $216 \mathrm{pp}$.

Grabenweger G. 1998: Die Parasitierung der Kastanienminiermotte (Cameraria ohridella Deschka \& Dimic) in Wien und Niederösterreich. Master Thesis, Dept. Terr. Ecol., Inst. Ecol. Conserv. Biol., University of Vienna, 79 pp.

Grabenweger G. 2003: Parasitism of different larval stages of Cameraria ohridella. Biocontrol 48: 671-684.

HellRIGL K. 2001: Neue Erkenntnisse und Untersuchungen über die Roßkastanien-Miniermotte Cameraria ohridella Deschka \& Dimic, 1986 (Lepidoptera: Gracillariidae). Gredleriana 1: 9-81.

Hellrigl K. 2003: Cameraria ohridella: a che punto siamo arrivati? Relazioni della: Giornata di Studio Sulle Principali Avversità dell' Ippocastano: 14 Febraio 2003; Università di Bologna, pp. 63-68.

Krehan H. 1997: Roßkastanienminiermotte - Vergleich der Bekämpfungsverfahren. Forstschutz Aktuell 19/20: 2-7.

Maceljski M. \& Bertie D. 1996: The horse chestnut leafminer Cameraria ohridella Deschka et Dimiæ (Lep.: Lithocolletidae) - a new dangerous pest in Croatia (in Croatian, English abstr.) Fragm. Phytomed. Herbol. 23: 9-18.

NOYES J.S. 2002: Interactive Catalogue of World Chalcidoidea on $C D-R O M$ (2001- second edition). Taxapad, Vancouver and The Natural History Museum, London.

Puchberger K.M. 1995: Zur Geschichte der ersten Ausbreitung von Cameraria ohridella Deschka \& Dimic 1986 in Österreich (Lepidoptera: Gracillariidae). Entomol. Nachr. Bl. 1: 2-3.

ŠEFrovÁ H. 2001: Control possibility and additional information on the horse-chestnut leafminer Cameraria ohridella Deschka \& Dimiæ (Lepidoptera: Gracillariidae). Acta Univ. Agric. Silvic. Mendel. Brun. 49: 121-127.

ZWÖLFER H. \& PSCHORN-WALCHER H. 1968: Wie verhalten sich Insektenparasiten gegenüber eingeschleppten, faunenfremden Wirten? Anz. Schädl-k. 4: 51-55.

Received May 14, 2003; revised September 5, 2003; accepted October 22, 2003 